\title{
PARTICULAR ASPECTS REGARDING ENTREPRENEUR AND ENTREPRENEURIAL CULTURE
}

\author{
Catalin Drob \\ "Vasile Alecsandri" University of Bacau \\ e-mail: catad@ub
}

\begin{abstract}
The goal of this article is to emphasize the main aspects which characterize the notions of entrepreneur, entrepreneurship and entrepreneurial culture. The notion of entrepreneur has been introduced in the economic literature since the late seventeenth century. Entrepreneurial culture is a newly concept that has been introduced in the economic literature since the 60s of last century. Entrepreneurial culture is a complex notion that refers to values, beliefs and attitudes shared in a society, which characterize entrepreneurial lifestyle. Also, this paper contains a study case, which consists in presentation and interpretation of the responses to a questionnaire regarding specific aspects of the entrepreneurship and entrepreneurial culture. The responses to this questionnaire show, among others, the student's interest for business and the entrepreneurial values which can contribute to business success.
\end{abstract}

\section{Keywords}

entrepreneur; entrepreneurial culture; students; economic development

\section{JEL Classification}

L26

\section{General consideration regarding entrepreneur, entrepreneurship and entrepreneurial culture}

In the economic theory, were proposed, along time, several definitions regarding the concept of entrepreneur. Initially, this notion has been used in the economic theory to describe the founder of a business enterprise.

Richard Cantillon (1680-1734) was considered the first economist who used the term of entrepreneur. In the economic theory, the Richard Cantillon's contribution regarding this term is that he argues that the entrepreneurial function is manifested in the economic system both at micro and macroeconomic level.

Jean-Baptiste Say (1767-1832) was another great economist who contributed to introduce the term of entrepreneur in the economic theory. Both R. Cantillon and J.B. Say considered that entrepreneurs are "risk-takers" because they risk investing their own money.

In the early twentieth century, Joseph Schumpeter was the one who gave a new meaning to the term of entrepreneur. In the Schumpeter's view, the entrepreneur is a man of action who has the courage, vision, creative spirit and ability to create something new. Also, Schumpeter highlighted the importance and the role of entrepreneurs in the economic development of a country.

At the end of the twentieth century, Peter Drucker has proposed a new approach concerning entrepreneurs and entrepreneurship based on the theories of J.B. Say and J. Schumpeter regarding the entrepreneur. In the Drucker's view, the entrepreneur is the person which seeking change, reacts to it and exploits it as an opportunity. Entrepreneurs realizes the change through the innovation. 
List of the economists who have approached the problematic of the entrepreneur and of the entrepreneurship is very long. Among the personalities who have made contributions to the development of economic theory in this area we can enumerate on F. H. Knight, M. Weber, L. Walras and I.M. Kirzner.

But what is the entrepreneurship? Entrepreneurship can be defined as a behavioral characteristic of the entrepreneur and, also, as a process. As stated by the Commission of the European Communities (2003), the entrepreneurship is the mindset and process to create and develop economic activity by blending risk-taking, creativity and/or innovation with sound management, within a new or an existing organization.

A relatively new term that relates to entrepreneurs and entrepreneurship is the entrepreneurial culture. Entrepreneurial culture can be considered a subtype of culture oriented towards entrepreneurship. As stated by Wong (2014), entrepreneurial culture can be defined as a set of values, beliefs and attitudes shared within an organization or a society and which characterizes entrepreneurial lifestyle.

The attributes and characteristics entrepreneurial culture arising from the definition of the entrepreneur and of the entrepreneurship. Thus, among the entrepreneurial culture characteristics we can include:

- Encouraging risk;

- Tolerating failure;

- Promoting innovation product

- Encourage the improvement and continuous change;

- Vision and passion for business etc.

Many authors who studied the relation between entrepreneurship and economic development have provided empirical evidences which shows that there is strong and positive relation between entrepreneurship and economic development. Also, as stated by Beugelsdijk (2007) the entrepreneurial culture is related to economic growth.

\section{Study about the student's vision regarding entrepreneurs and entrepreneurial culture}

The objective of this research was to shows the students' interest regarding development an own business and the to identify the true values who should characterize an entrepreneur and an authentic entrepreneurial culture.

The method used in this article is based on a questionnaire applied on 200 students of the "Vasile Alecsandri" University of Bacau, Engineering Faculty, who are in the last year of study. The questionnaire included the following questions:

1. Are you interested in developing your own business?

a) Yes; b) No; c) I don't know.

2. When do you think that it's time to open a business?

a) During the faculty; b) Immediately after the graduation of the faculty; c) After gaining experience in business/work; d) When will appear a business opportunity; e) When I will have enough capital.

3. What would the reasons for which you would open a business?

a) Financial independence; b) Personal fulfillment; c) Chance to implement personal ideas; d) The possibility of being own boss.

4. In your opinion, which are the main factors that contribute to business success?

a) Vision; b) Risk-taking; c) Identification and exploit of opportunities; d) Business ethics; e) Motivation; f) Passion; g) Enthusiasm; h) Chance; i) Perseverance; j) Innovation.

5. In your opinion, which are the main obstacles to opening your own business?

a) Lack of capital; b) The uncertainty of the economic environment; c) Fear of failure;

d) Excessive bureaucracy; e) Fierce competition in the business; f) Lack of opportunities/business idea; g) Lack of entrepreneurial skills. 
6. Which do you think are the main risks arising from opening a business?

a) Possibility to record a professional failure; b) Possibility to record a personal failure;

c) The possibility of losing everything (property, family etc.); d) Neglecting the family in the detriment of business.

7. In which measure do you thing that your faculty prepares you to become an entrepreneur?

a) In a large extent; b) In a medium extent; c) In a lesser extent.

\section{Data analysis}

At the first question (Are you interested in developing your own business?) $79 \%$ of the students questioned have responded that are interested in developing a small business and only $4 \%$ have responded that are not interested in developing a business.

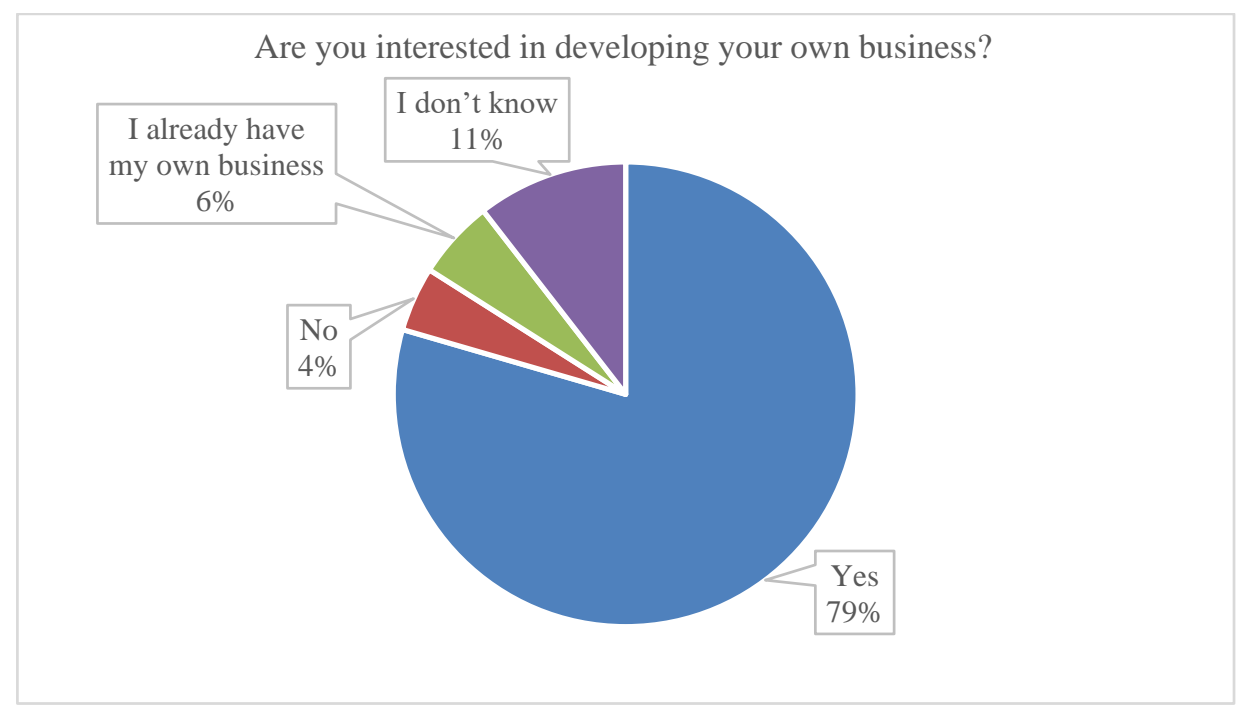

Figure 1. Student's interest in developing a business

Source: student's questionnaire responses (question no.1)

At the second question (When do you think that it's time to open a business?) the students questioned have responded as follows:

- 3\% of the students questioned have chosen the answer option "a" (During the faculty);

- $12 \%$ of the students questioned have chosen the answer option "b" (Immediately after the graduation of the faculty;

- $50 \%$ of the students questioned have chosen the answer option "c" (After gaining experience in business/work);

- $25 \%$ of the students questioned have chosen the answer option "d" (When will appear a business opportunity);

- $10 \%$ of the students questioned have chosen the answer option "e" (When I will have enough capital).

At the third question the students questioned have responded that financial independence is the main reason for they would open a business $(67 \%$ of the students questioned) followed by the chance to implement personal ideas $(41 \%$ of the students questioned) and the personal fulfillment (35\% of the students questioned).

At the fourth question the students questioned have responded that the main factors that contribute to business success are followings: 
- motivation ( $51 \%$ of the students questioned);

- vision ( $40 \%$ of the students questioned);

- passion (38\% of the students questioned);

- identification and exploit of opportunities (36\% of the students questioned);

- risk-taking ( $34 \%$ of the students questioned);

- perseverance ( $26 \%$ of the students questioned);

- chance ( $19 \%$ of the students questioned);

- innovation ( $16 \%$ of the students questioned) etc.

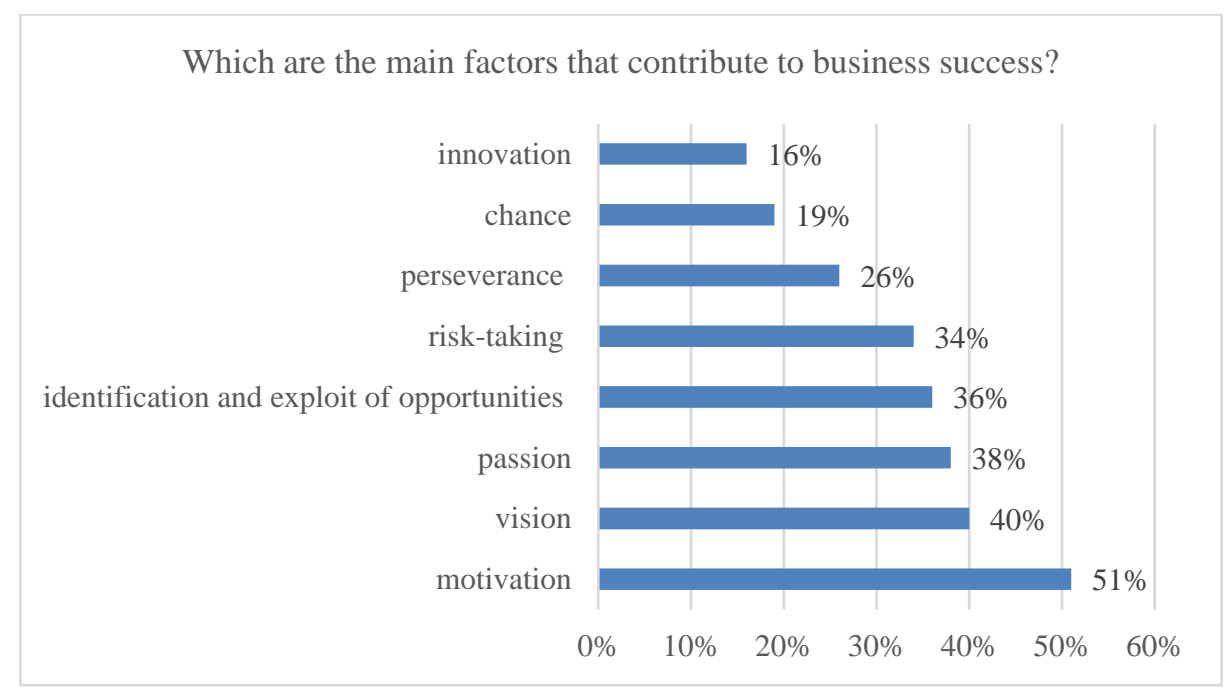

Figure 2. Main factors that contribute to business success Source: student's questionnaire responses (question no.4)

At the fifth question the students questioned have responded that the main obstacles to opening their own business are followings:

- lack of capital ( $77 \%$ of the students questioned);

- fear of failure ( $48 \%$ of the students questioned);

- excessive bureaucracy (36\% of the students questioned);

- fierce competition in the business (33\% of the students questioned);

- the uncertainty of the economic environment ( $31 \%$ of the students questioned);

- lack of entrepreneurial skills ( $25 \%$ of the students questioned);

- lack of opportunities / business idea ( $15 \%$ of the students questioned). 


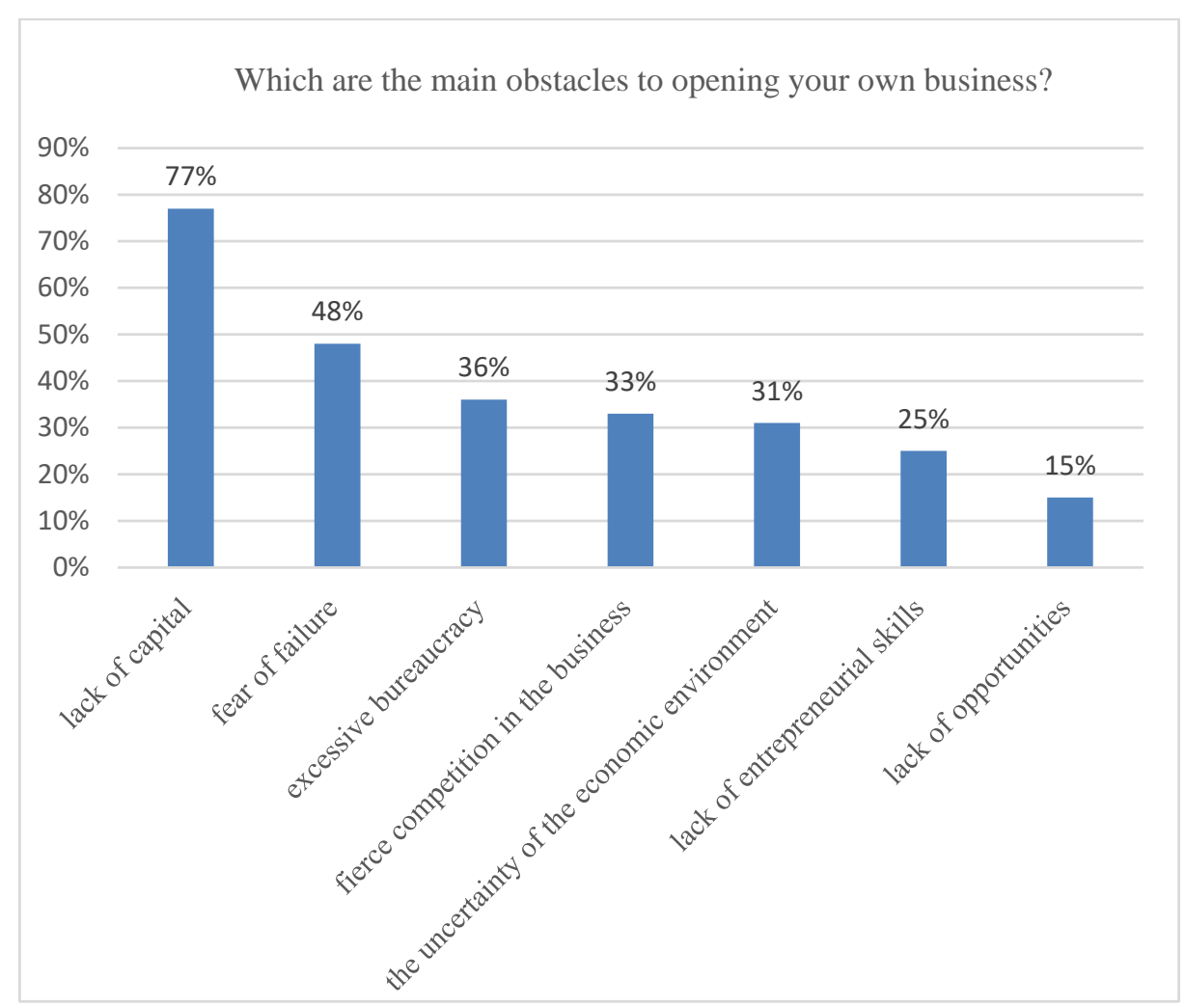

Figure 3. Main obstacles to opening a business

Source: student's questionnaire responses (question no.5)

At the sixth question the students questioned have responded that the main risks regarding to open a business are followings:

- possibility to record a professional failure (76\% of the students questioned);

- possibility of losing everything (43\% of the students questioned);

- neglecting the family in the detriment of business (29\% of the students questioned);

- possibility to record a personal failure ( $22 \%$ of the students questioned).

At the last question the students have responded that during faculty they were prepared to become entrepreneurs in a large and medium extent ( $80 \%$ of the students questioned) and in a lesser extent (just $20 \%$ of the students questioned).

\section{Conclusions}

As stated by Berger (1991), entrepreneurship and entrepreneurial culture are closely related to the economic development of a country. Increasing the numbers of entrepreneurs and the development of the entrepreneurial culture contribute to economic development and to prosperity of the country. Also, entrepreneurship contributes to social wealth by creating new markets, new industries, new jobs and so on.

The present study highlights the fact that among future graduates of the "Vasile Alecsandri" University of Bacau, Engineering Faculty there is a great desire to become entrepreneurs and to succeed as entrepreneurs (79\% of the students questioned have responded that are interested in developing a small business). In the opinion of $50 \%$ of respondents, this intent to initiate and develop a business will be taken into account, mainly, after gaining experience in work. In the view of future 
graduates, to succeed in a business, the entrepreneur must have in among others, motivation, vision and passion (in this order). Even though there are many barriers to business success (in particular, lack of capital, fear of failure, excessive bureaucracy etc.) and many risks (especially of professional failure etc.) our students are convinced that knowledge acquired in faculty will help them to become successful entrepreneurs. In this context, the role of the professors in the universities becomes more and more important: to train the specialists of tomorrow and, in the same time, to form the future entrepreneurs. As stated by The development of a true entrepreneurial culture among current students will have beneficial effects in the future in terms of their success in the business field, and also in terms of overall development of the national economy.

\section{References}

Berger, B. (1991), The culture of entrepreneurship, Institute for Contemporary Studies, San Francisco, California.

Beugelsdijk, S. (2007), Entrepreneurial Culture, Regional Innovativeness and Economic Growth, Journal of Evolutionary Economics, vol. 17, issue 2, p. 187-210.

Commission of the European Communities (2003), Green Paper Entrepreneurship in Europe, Enterprise Publications, Brussels, available at: http://ec.europa.eu/invest-in research/pdf/download_en/ entrepreneurship_ europe.pdf

Tong, X.F., Tong, D.Y.K., Loy, L.C. (2011), Factors influencing entrepreneurial intention among university students, International Journal of Social Sciences and Humanity Studies, Vol 3, No 1, p. 487-496, available at: http://www.sobiad.org/ejournals/journal_ijss/arhieves/2011_1/xue_fa_tong.pdf

Wong, Matthew A. (2014) Entrepreneurial culture: Developing a theoretical construct and its measurement, University of Western Ontario - Electronic Thesis and Dissertation Repository, Paper 2138, available at: http://ir.lib.uwo.ca/cgi/viewcontent.cgi?article=3435\&context=etd. 